\title{
An approach to evaluate the effects of nonlinear traveling joints on dynamic behavior of large machine tools
}

\author{
Wen Zheng Ding • Xiao Diao Huang • Mu Lan Wang • \\ Song Qing Zhu
}

Received: 31 July 2012 / Accepted: 25 January 2013 /Published online: 12 February 2013

(C) The Author(s) 2013. This article is published with open access at Springerlink.com

\begin{abstract}
In order to select the best possible design from various candidates based on structure configurations of traveling components, it is essential to evaluate the effects of traveling joints on dynamic behavior of large machine tools. Firstly, regression analysis and energy method were used to determine the nonlinear parameters of the metal-plastic joints. Then, a nonlinear receptance coupling approach was used to establish a simplified model of a large machine tool including nonlinear joints. The evaluations of the large machine tool were analyzed with different milling forces. The results show that the nonlinearity of traveling joints significantly influences the resonant frequency and the response amplitudes. Experimental verifications were performed on a prototype of a large machine tool for milling large gears.
\end{abstract}

Keywords Metal-plastic joint · Nonlinear · Dynamic . Large machine tools

\section{Introduction}

Increasing demands for large parts, especially in aerospace industry, electric power industry, and shipping

W. Z. Ding $\cdot$ X. D. Huang $(\bowtie)$

School of Mechanical and Power Engineering, Nanjing University of Technology, Nanjing, People's Republic of China

e-mail: njgdsk139@126.com

W. Z. Ding $\cdot$ M. L. Wang $\cdot$ S. Q. Zhu

Jiangsu Key Laboratory of Advanced Numerical Control

Technology, Nanjing Institute of Technology, Nanjing, People's

Republic of China industry, is boosting interest in large machine tools [1]. These large parts which were previously fabricated are now machined from monolithic blocks. Improvement of large parts quality requires better precision of the large machine tool, while a large machine tool was not associated with the concepts of high precision in previous years [2]. This requires good dynamic characteristics of large machine tools. Commonly, the machine's dynamic behavior is represented in terms of frequency response function (FRF) $[3,4]$. During the design stage of large machine tools, various candidate designs based on structure configurations of traveling components are needed to consider to select the best possible design. So, it is essential to evaluate the dynamic behavior before construction of the machine. By the way, most of the deformations in machine tools are taken up at the machine joints; therefore, the dynamic behavior of large machine tools highly depends to a large extent on the traveling joints [5].

For large machine tools, a common discussion in design is the comparison of slide guides vs. linear guides. Slide guides are valued for their ability to absorb large cutting force and vibrations, while linear guides offer the advantage of faster movement and low friction. When machining large parts, slide guides were typically used because the parts may need heavy cutting and may be on the machine for many hours. Recently, there has been progressive replacement of metal-metal slide guides by metal-plastic ones, especially for large machines. In metal-plastic guides, some special polyethylene, which was characterized by considerable amounts of compliance and damping, was used as covering materials to reduce the friction and the wear of the joints [6]. Traditionally, the vibrations and the corresponding natural frequencies of the machine were analyzed by finite 


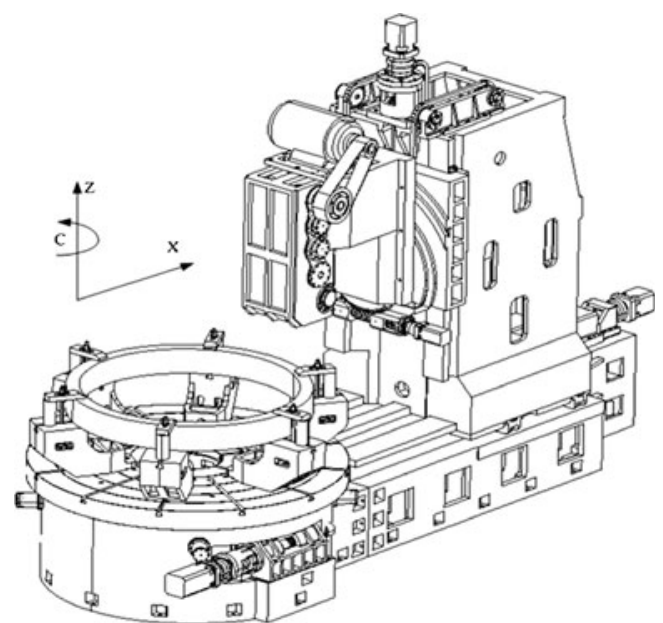

Fig. 1 A large machine tool for milling big gears

element method (FEM) and the traveling joints were treated as linear components $[7,8]$. In reality, it is found that most practical structures do not comply with the assumption of linearity [5, 9-13]. The metal-plastic traveling joints may introduce nonlinearity in the large machine structure. This nonlinearity of traveling joints may result in significant variation in magnitude and natural frequency of machine's FRF [14], which is not taken into account in FEM.

In design phases, the evaluation regarding dynamic behavior of a large machine tool becomes difficult because of such nonlinear traveling joints. Several papers have reported on modeling the stiffness and damping characteristics of machine joints [15-18]. Substructure synthesis methods [19] and impedance coupling methods [20] have been developed and used extensively in the dynamic analysis of assembled structures. However, the nonlinear effect of traveling joints was also not considered in these methods. The purpose of this paper

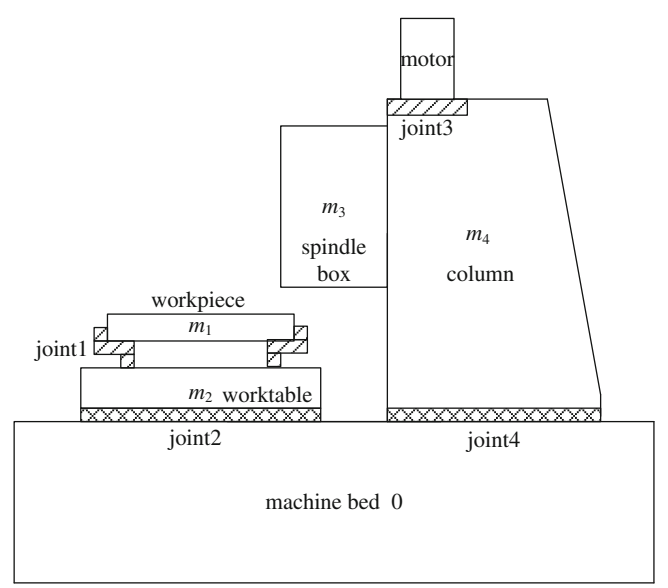

Fig. 2 Sketch of joints in the machine tool

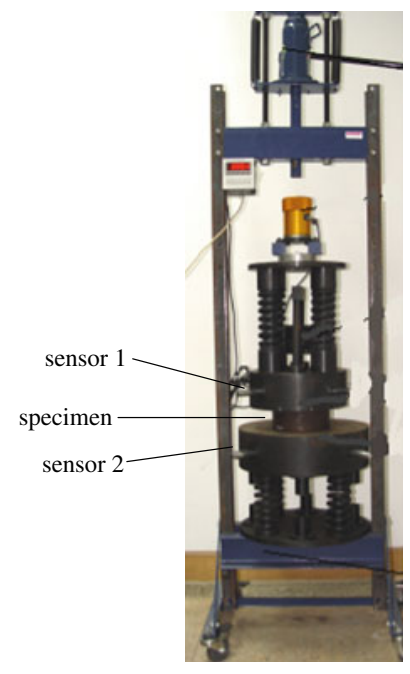

Fig. 3 Experimental setup for parameters of joints

is to describe a systematic way to evaluate the nonlinear effect of metal-plastic joints on dynamic behavior of large machine tools using an improved version of impedance coupling methods which incorporates nonlinear joints. The manuscript was organized as follows: The experimental determination of the nonlinear parameters for the metal-plastic joints was performed in Section 2. A simplified model to evaluate the dynamic behavior of a large machine tool including nonlinear joints was established in Section 3. Based on the model, the effect of traveling joints on dynamic behavior of a large machine tool was evaluated in Section 4. Additionally, its validation through comparisons with experimental results was also reported. And finally, conclusions were offered in Section 5. It was illustrated throughout the paper by the application to a large machine tool for milling large gears named SKXC-4000, as shown in Fig. 1.

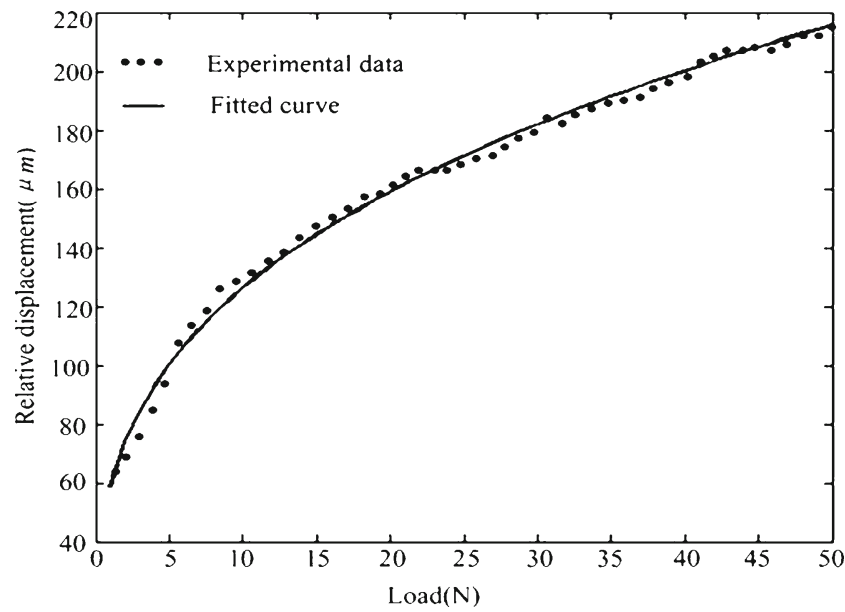

Fig. 4 Relationship between external load and relative displacement 


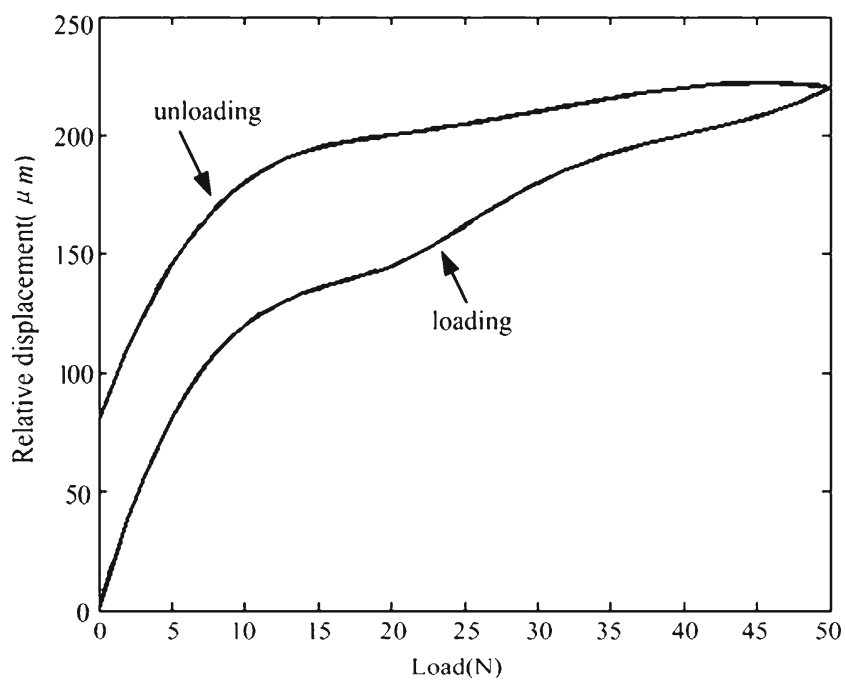

Fig. 5 Hysteresis loop under loading and unloading

\section{Experimental determination of nonlinear parameters for metal-plastic joints}

\subsection{Descriptions of joints in the large machine tool}

The structure of the large machine tool for milling big gears was a very common type of machine tool design with a moving column. The column was equipped with a spindle box with a maximum speed of $170 \mathrm{rpm}$ and maximum power of $60 \mathrm{~kW}$. Many fixed joints and traveling joints were included in this machine, whose sketch was shown in Fig. 2. The workpiece was mounted on the worktable by bolt clamps, which constituted the fixed joint 1. The worktable was connected to the machine bed by the round metal-plastic guide, which constituted the traveling joint 2. Although the spindle box was connected to the column by a slide guide, the normal contact pressure on the guide applied by the spindle box was not high, so the dominate vibration was transferred to the motor cabinet through the feed screw nut. The motor cabinet was mounted on the column by bolts, which constituted the fixed joint 3 . The metal-plastic guide which was connected the column and the machine bed constituted the traveling joint 4 . The machine bed was assumed as a connecting base which was perfectly rigid.

An ultra high molecular weight polyethylene was used as covering materials in the metal-plastic guides of the large
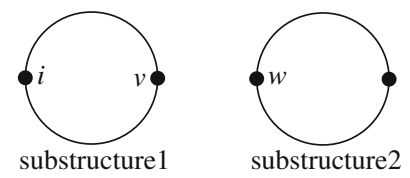

Fig. 6 Individual substructures

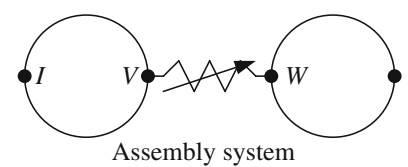

Fig. 7 Assembled structure

machine tool for milling big gears. The model accounting for the traveling joints is based on the assumption that the metal component is rigid and all compliance may be attributed to the plastic component. The objective of the model is to describe the relationship between the restoring force with respect to the relative displacement $\Delta x$ and the relative velocity $\Delta \dot{x}$. The restoring force function was expressed as

$P(\Delta x, \Delta \dot{x})=p(\Delta x)+c \Delta \dot{x}$

where $p(\Delta x)$ is the restoring force due to the stiffness term alone, and $c \Delta \dot{x}$ represents the contribution due to the viscous damping. Subsequently, experiments were done to determine the stiffness, and the energy method was used to determine the damping coefficient.

\subsection{Determination of stiffness term}

There are several factors which influence the stiffness of the metal-plastic joints interactively, such as the external load, the lubricated condition, and the surface roughness. Essentially, the stiffness of the metal-plastic joints was nonlinear. In this experiment, dimension of the specimen for the metal-plastic joints was $900 \mathrm{~mm}^{2}$, and the surface roughness was $3.01 \mu \mathrm{m}$. The specimen was clamped in the experimental setup shown in Fig. 3. With well-lubricated conditions, the external load on the specimen was varied from 1 to $50 \mathrm{~N}$. Two TESA sensors were aligned symmetrically to measure the relative displacement on either side of the specimen to ensure that only normal translation was observed when external load was applied. A total of 50 experiments were done and the results obtained from experiments were shown in Fig. 4. Regression analysis was used to find the mathematical model of $p(\Delta x)$. The data were fitted with a cubic power curve using the least square estimation, and it was derived as

$p(\Delta x)=k(\Delta x)^{3}$

where $k=4.99 \times 10^{12} \mathrm{~N} / \mathrm{m}^{3}$.

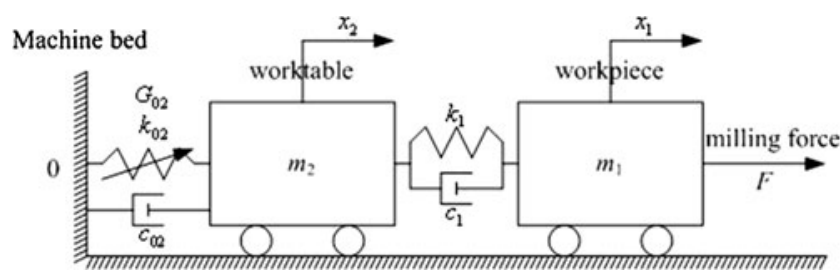

Fig. 8 Model of assembled structure for workpiece-worktable-machine bed 


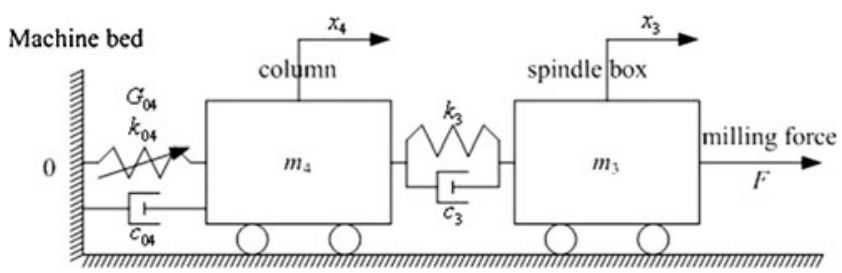

Fig. 9 Model of assembled structure for spindle box-column-machine bed

\subsection{Determination of damping coefficient}

The damping coefficient was calculated based on the hysteresis loop (shown in Fig. 5) recorded during experiments with conditions of loading and unloading on the specimen. It was found that the net energy loss due to damping per cycle was about $20 \%$ of the maximum potential energy, thus damping played a significant role in the system dynamics. Therefore, the viscous damping was assumed to describe the joint damping characteristics. Using the energy method [21], it was possible to get the damping coefficient, which was defined as

$c=\frac{\Delta U}{U_{\max }}=0.2384 \mathrm{Ns} / \mathrm{m}$

where $c$ is the damping coefficient, $\Delta U$ is the energy loss, and $U_{\max }$ is maximum potential energy.

\section{Modeling of the large machine tool structure including nonlinear joints}

\subsection{Approach to analyze the effect of nonlinear joints}

Owing to their relatively rigidity, the workpiece, worktable, machine bed, clamps fixed joint, and bolts fixed joint were all represented as linear models. Nonlinear dynamics were introduced into the machine tool structure through the metal-plastic joints only. The nonlinear receptance coupling approach (NLRCA) was used in this paper to analyze the effect of traveling joints. This method was developed by Ewins et al. [22].

NLRCA was able to represent the response of a coupled structure with local nonlinear elements to various input excitations based on the determined frequency response of individual modules of pre-coupled structure to various input excitations. The coupled structure included all the modules of the precoupled structure along with the joints. The analysis process was divided into two stages: (a) before coupling and (b) after coupling. The coupling was related to structures and coordinates. All the structures in the before coupling stage were called "individual substructure," and the coupled structure in the after coupling stage was called "assembled structure." The coordinates were also divided into "connection coordinates" and "internal coordinates." The individual substructures to be connected were shown in Fig. 6, and the assembled structure with a nonlinear joint was shown in Fig. 7.

The coordinates in the individual substructures were represented by small letters, and the coordinates in the assembled structure were represented by capital letters. The connection was represented by a pair of connected coordinates $(v, w)$, and $i$ is the internal coordinate. The response of the structure in the before coupling stage was expressed as

$$
\left\{\begin{array}{c}
x_{i} \\
x_{v} \\
x_{w}
\end{array}\right\}=\left[\begin{array}{lll}
h_{i i} & h_{i v} & h_{i w} \\
h_{v i} & h_{v v} & h_{v w} \\
h_{w i} & h_{w v} & h_{w w}
\end{array}\right]\left\{\begin{array}{l}
f_{i} \\
f_{v} \\
f_{w}
\end{array}\right\}
$$

where $x_{i}$ is the displacement in the $i$ coordinate, $h_{v w}$ is the receptance matrix of the dynamic compliance between the coordinates $v$ and $w$, and $f_{i}$ is the force applied in the $i$ coordinate.

In the after coupling stage, the response of the structure was expressed as

$\left\{\begin{array}{l}X_{I} \\ X_{V} \\ X_{W}\end{array}\right\}=\left[\begin{array}{lll}H_{I I} & H_{I V} & H_{I W} \\ H_{V I} & H_{V V} & H_{V W} \\ H_{W I} & H_{W V} & H_{W W}\end{array}\right]\left\{\begin{array}{c}F_{I} \\ F_{V} \\ F_{W}\end{array}\right\}$.

The equilibrium conditions of forces were given as

$$
\left\{\begin{array}{c}
F_{V}=F_{W}=f_{v}+f_{w} \\
f_{i}=F_{I}
\end{array} .\right.
$$

The compatibility conditions of displacements were given as

$$
\left\{\begin{aligned}
x_{i} & =X_{I} \\
x_{v} & =X_{V} \\
x_{w} & =X_{W} \\
x_{v}-x_{w} & =-f_{v} / G_{v w}
\end{aligned}\right.
$$

$$
\left\{\begin{aligned}
x_{i} & =X_{I} \\
x_{v} & =X_{V} \\
x_{w} & =X_{W} \\
x_{w}-x_{v} & =-f_{w} / G_{v w}
\end{aligned}\right.
$$

where $G_{v w}$ is the describing function of the joint dynamic compliance which is a function of relative displacement

\begin{tabular}{|c|c|c|c|c|c|}
\hline$m_{1} / \mathrm{kg}$ & $m_{2} / \mathrm{kg}$ & $k_{1} / \mathrm{MN} \mathrm{m}^{-1}$ & $c_{1} / \mathrm{Nsm}^{-1}$ & $k_{02} / \mathrm{TN} \mathrm{m}^{-3}$ & $c_{02} / \mathrm{Nsm}^{-1}$ \\
\hline 1,000 & 15,000 & 3 & 300 & 4.99 & 0.2384 \\
\hline
\end{tabular}

Table 1 Model parameters of workpiece-worktable-machine bed 
Table 2 Model parameters of spindle box-column-machine bed

\begin{tabular}{llllll}
\hline$m_{3} / \mathrm{kg}$ & $m_{4} / \mathrm{kg}$ & $k_{2} / \mathrm{MN} \mathrm{m}^{-1}$ & $c_{2} / \mathrm{Nsm}^{-1}$ & $k_{04} / \mathrm{TN} \mathrm{m}^{-3}$ & $c_{04} / \mathrm{Nsm}^{-1}$ \\
\hline 4,000 & 9,000 & 3 & 300 & 4.99 & 0.2384 \\
\hline
\end{tabular}

between the coordinates $v$ and $w$. Obviously, this describing function will be different values at different response amplitudes.
Consequently, the response of the structure in the after coupling stage was derived by the receptance matrices in the before coupling stage as

$\left\{\begin{array}{l}X_{I} \\ X_{V} \\ X_{W}\end{array}\right\}=\left\{\left[\begin{array}{lll}h_{i i} & h_{i v} & h_{i w} \\ h_{v i} & h_{v v} & h_{v w} \\ h_{w i} & h_{w v} & h_{w w}\end{array}\right]-\left[\begin{array}{c}h_{i v}-h_{i w} \\ h_{v v}-h_{v w} \\ h_{w v}-h_{w w}\end{array}\right](B)^{-1}\left[\begin{array}{c}h_{i v}-h_{i w} \\ h_{v v}-h_{v w} \\ h_{w v}-h_{w w}\end{array}\right]^{T}\right\}\left\{\begin{array}{c}F_{I} \\ F_{V} \\ F_{W}\end{array}\right\}$

where

$B=h_{v v}+h_{w w}+1 / G_{v w}-h_{v w}-h_{w v}$.

\subsection{A simplified model of the large machine tool structure}

Figure 8 shows the assembled structure of workpieceworktable-machine bed, which is represented by 2 degrees of freedom forced vibration system. The workpiece and the worktable were assumed as rigid bodies with equivalent mass $m_{1}$ and $m_{2}$. The fixed joint 1 was represented by a linear spring with stiffness $k_{1}$ and a viscous damper with damping coefficient $c_{1}$ followed ref. [23]. The traveling joint 2 was represented by a nonlinear element with the describing function of the joint dynamic compliance $G_{02} . F$ was the magnitude of milling force applied on the workpiece. Similarly, the model of assembled structure for spindle box-columnmachine bed was shown in Fig. 9.

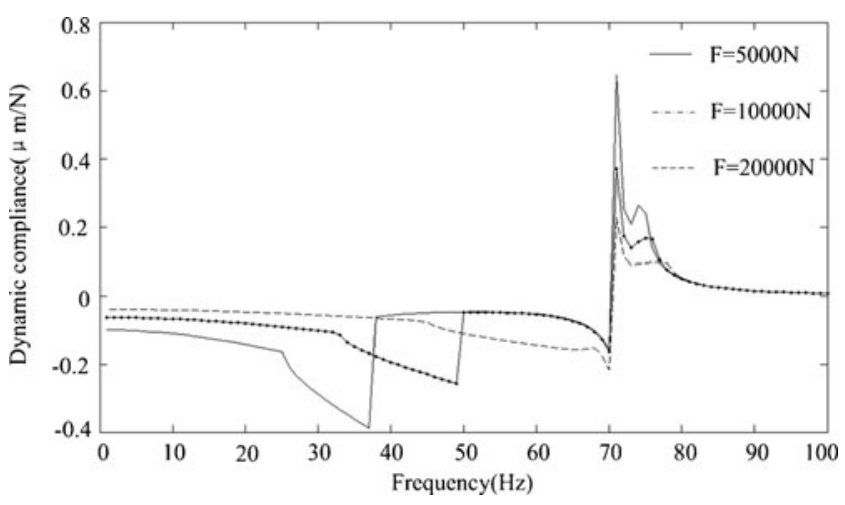

Fig. 10 Dynamic compliance of assembled structure for workpiece-worktable-machine bed

\section{Evaluation of the traveling joints effect on dynamic behavior of the large machine tool}

In Fig. 8, the internal and connection coordinates were defined as $i=\{1\}, v=\{2\}$, and $w=\{0\}$, where 0 represented machine bed as connection base, and 1 and 2 represented coordinates on $m_{1}$ and $m_{2}$ respectively. Consequently, the receptance metrics of the dynamic compliance in Eq. (9) were determined as

$h_{01}=h_{10}=h_{20}=h_{00}=h_{02}=0$.

The receptance metrics of the dynamic compliance between the workpiece and the worktable were derived from the equation of motion which was described as

$$
\left[\begin{array}{cc}
m_{1} & 0 \\
0 & m_{2}
\end{array}\right]\left[\begin{array}{c}
\ddot{x}_{1} \\
\ddot{x}_{2}
\end{array}\right]+\left[\begin{array}{cc}
c_{1} & -c_{1} \\
-c_{1} & c_{1}
\end{array}\right]\left[\begin{array}{l}
\dot{x}_{1} \\
\dot{x}_{2}
\end{array}\right]+\left[\begin{array}{cc}
k_{1} & -k_{1} \\
-k_{1} & k_{1}
\end{array}\right]\left[\begin{array}{l}
x_{1} \\
x_{2}
\end{array}\right]=\left[\begin{array}{c}
F \\
0
\end{array}\right] .
$$

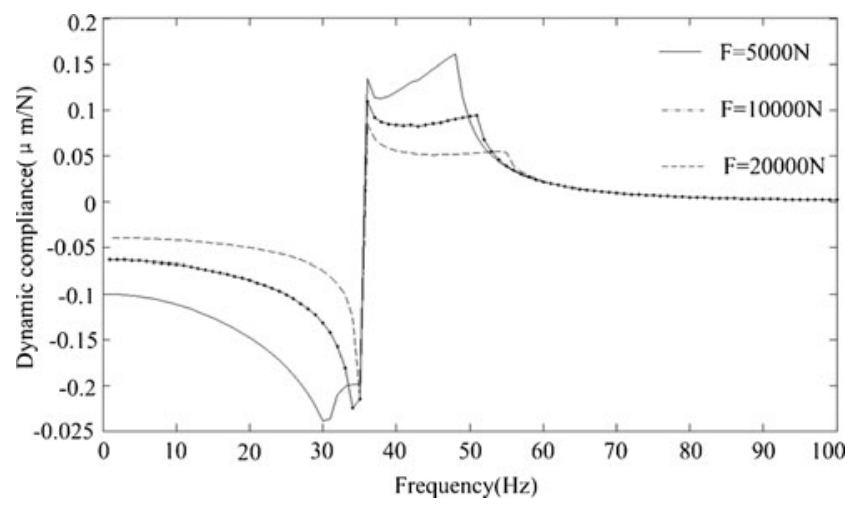

Fig. 11 Dynamic compliance of assembled structure for spindle boxcolumn-machine bed 


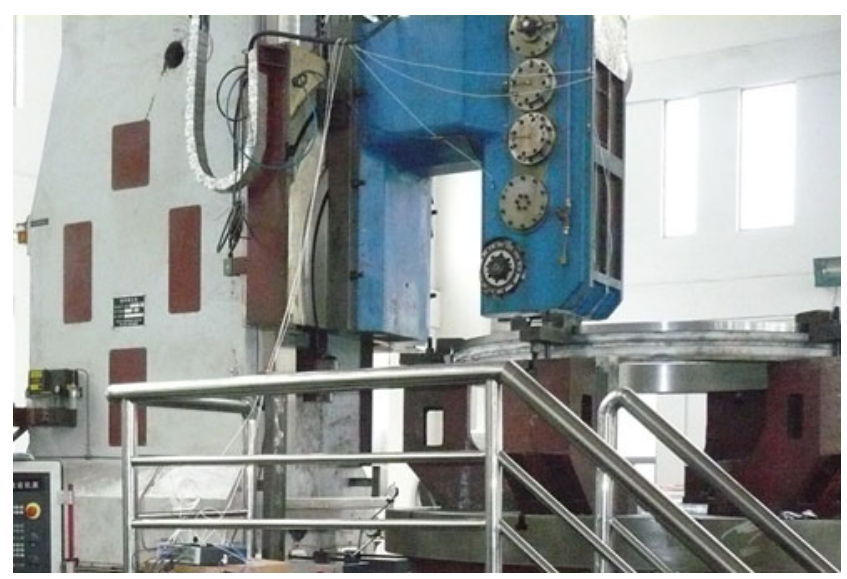

Fig. 12 Prototype of the large machine tool for milling big gears

So, the receptance matrix for the workpiece and the worktable was expressed as

$$
\left[\begin{array}{ll}
h_{11} & h_{12} \\
h_{21} & h_{22}
\end{array}\right]=\left[\begin{array}{ll}
-m_{1} \omega^{2}+j c_{1} \omega+k_{1} & -j c_{1} \omega-k_{1} \\
-j c_{1} \omega-k_{1} & -m_{2} \omega^{2}+k_{1}+j c_{1} \omega
\end{array}\right]^{-1}
$$
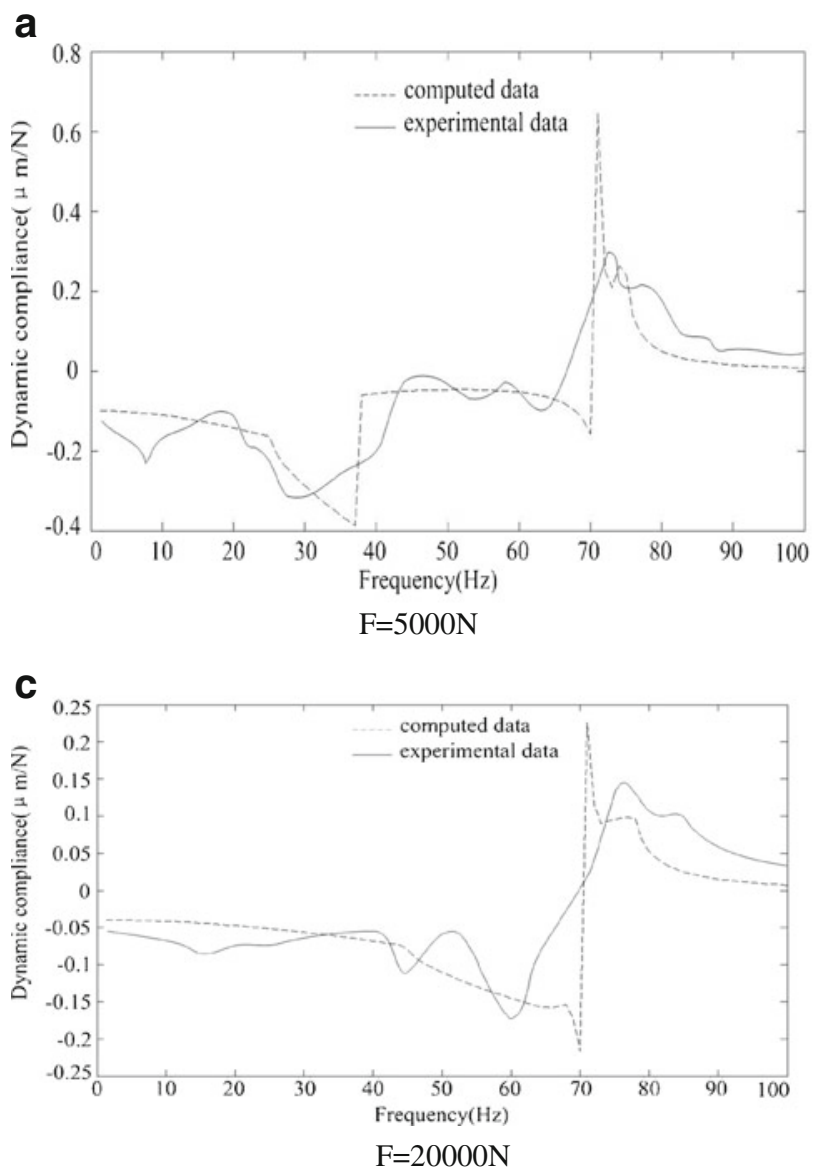

Consequently, Eq. (10) was derived as

$B=h_{22}+1 / G_{02}$

where $G_{02}$ can be calculated according to the Eq. (1). Based on the describing function method [24], the input was a harmonic signal which was defined as

$\Delta x=A \sin \omega t$

where $A$ was the amplitude of the input signal. Thus, the fundamental component of the response for the restoring force was derived as

$P(\omega)=\frac{3}{4} k_{02} A^{3} \sin \omega t+j c_{02} \omega A \sin \omega t$

so $G_{02}$ was obtained as

$G_{02}=\frac{3}{4} k_{02} A^{2}+j c_{02} \omega$

where $A$ was $x_{2}$ and $\omega$ was the frequency. Equation (9) can

b

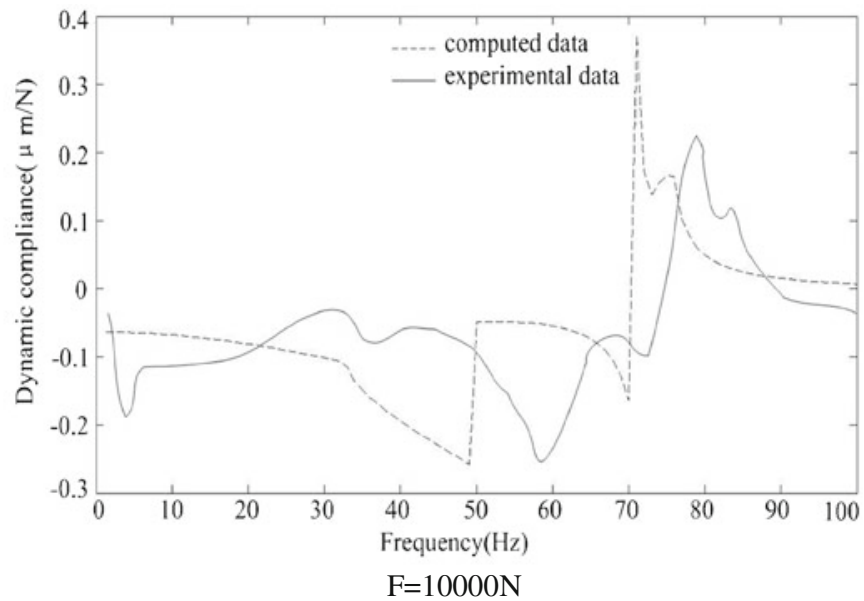

Fig. 13 a-c Computed and measured dynamic compliance of assembled structure for workpiece-worktable-machine bed 
a

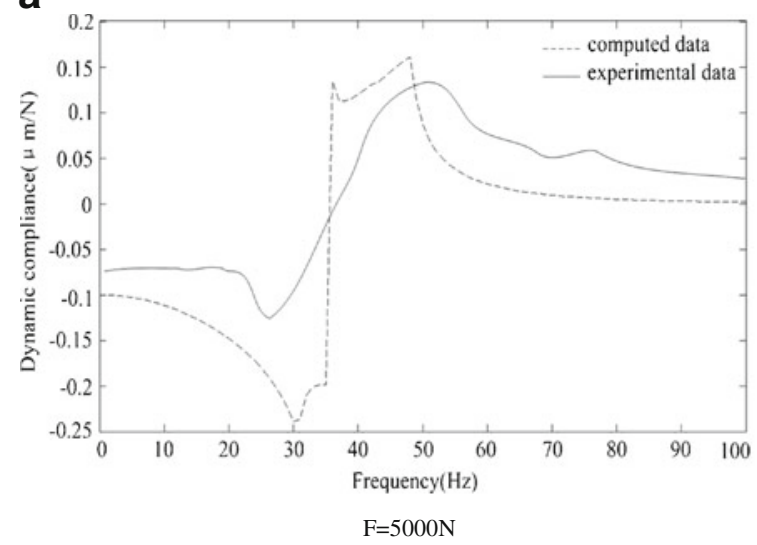

C

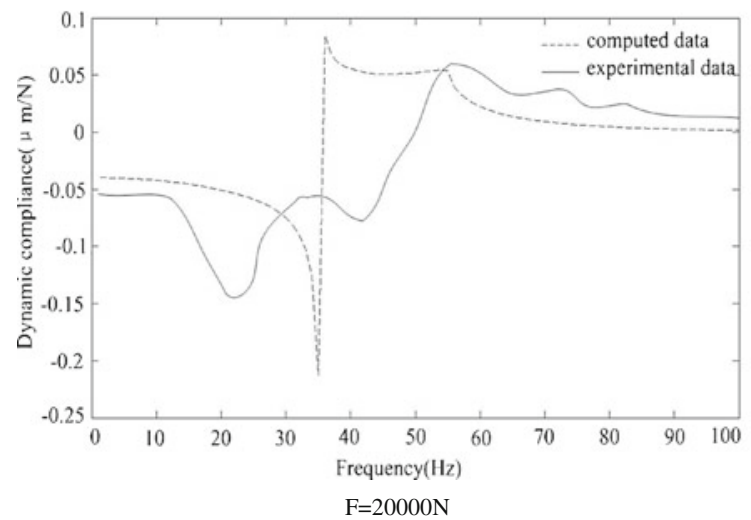

b

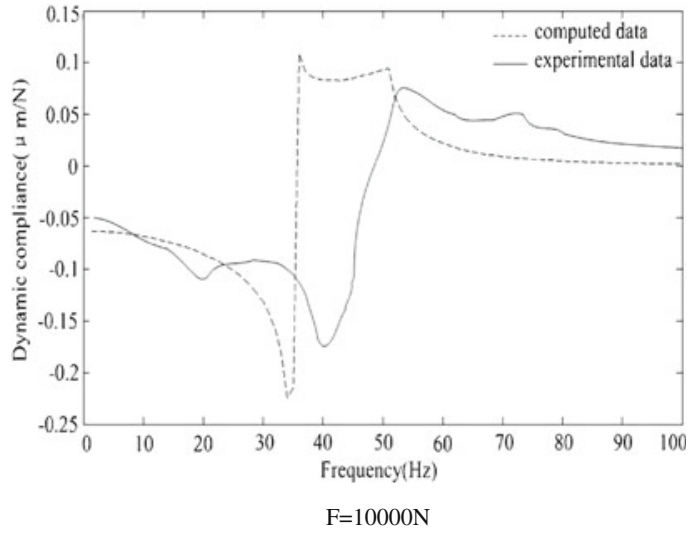

Fig. 14 a-c Computed and measured dynamic compliance of assembled structure for spindle box-column-machine bed

be expressed in this case as

$$
\left\{\begin{array}{l}
X_{1} \\
X_{2} \\
X_{0}
\end{array}\right\}=\left\{\left[\begin{array}{ccc}
0 & h_{12} & 0 \\
h_{21} & h_{22} & 0 \\
0 & 0 & 0
\end{array}\right]-\left[\begin{array}{c}
h_{12} \\
h_{22} \\
0
\end{array}\right](B)^{-1}\left[\begin{array}{c}
h_{12} \\
h_{22} \\
0
\end{array}\right]^{T}\right\}\left\{\begin{array}{l}
F \\
0 \\
0
\end{array}\right\} .
$$

The values of the model parameters were given in Tables 1 and 2. Figures 10 and 11 illustrate the results of Eq. (18) under different milling forces. Therefore, the amplitude of the milling force is important to estimate the dynamic behavior of the large machine tool accurately. Measurements of the milling force were carried out on the prototype of the large machine tool for milling big gears shown in Fig. 12. The milling force varied from 5,000 to $20,000 \mathrm{~N}$ when the feed rate changed from 150 to $270 \mathrm{~mm} / \mathrm{min}$ at the spindle speed of $100 \mathrm{rpm}$ and the tool diameter of $400 \mathrm{~mm}$ for machining the gear of $42 \mathrm{CrMo}$. For the assembled structure of workpiece-worktable-machine bed, when the milling force ranged from 5,000 to $20,000 \mathrm{~N}$, the maximum dynamic compliance changed from 0.692 to $0.275 \mu \mathrm{m} / \mathrm{N}$. Because of the effect of the nonlinear joints, the amplitude of the dynamic compliance decreased with increasing of the milling force. In other words, the dynamic compliance became weak inversely when the cutting force increased. The resonant frequency also changed with the variation of the milling force. Otherwise, the number of the resonant frequency was more than the number of freedom degrees of the assembled structure, and the jump phenomenon was observed in Figs. 10 and 11 . By comparing Figs. 10 and 11, we can observe that the nonlinear traveling joints have little influence on assembled structure of spindle-column-machine bed since the spindle box has a larger mass than the workpiece.

In order to verify the validity and efficiency of the above analysis, experimental tests have been performed on the prototype shown in Fig. 12. Hammer tests were carried out on the assembled structure of workpiece-worktable-machine bed and the assembled structure of spindle box-column-machine bed, respectively. The LMS vibration testing and analysis systems were used in the test, and the impact hammer in use was $086 \mathrm{C} 42$ produced by U.S. PCB. The testing accelerometer was 356A15 piezoelectric accelerometer. The comparisons between experimental results and theoretical calculations were shown in Figs. 13 and 14. Some deviations between the experimental records and the theoretical calculations were unavoidable because 
of the complexity of the experimental machine tool. Noise of the environment was also responsible for these deviations, while the evolution of the experimental records consisted with the theoretical calculations. The nonlinear dynamic characteristics were also observed in the experimental results.

\section{Conclusions}

The nonlinear effect of metal-plastic joints on dynamic behavior of large machine tools must be taken into account during the design stage so as to select the best candidate design. The study presented in this paper made it possible to evaluate the influence of the nonlinear joints. This proposed approach made use of the NLRCA which incorporated the effects of local nonlinear joints. Experimental results obtained from the prototype of the large machine tool for milling big gears were used to validate the approach. It was shown that the dynamic compliance became weak inversely when the cutting force increased, and the resonant frequency also changed with the variation of the exciting forces. The nonlinearity of traveling joints caused the uncertainty of the dynamic behavior of the machine tool. In order to further improve the dynamic performance of large machine tools, future work will focus on investigation of controlling the nonlinear vibration by modifying the mechanical structure or tuning the controller parameters in more detail. For this purpose, the coupled model with mechanical structure and control system as well as the corresponding verification tests has been planned.

Acknowledgments This research was supported by the National Natural Science Foundation of China, grant no. 51175242, Innovation Foundation of Nanjing Institute of Technology, grant no. CKJ2010014, and Key University Science Research Project of Jiangsu Province, grant no. 12KJA460002. The authors also wish to acknowledge contributions to this work of Nanjing Gongda CNC Technology Co., Ltd. for its assistance in experiments.

Open Access This article is distributed under the terms of the Creative Commons Attribution License which permits any use, distribution, and reproduction in any medium, provided the original author(s) and the source are credited.

\section{References}

1. Acedo EG, Olarra A, Lopez LN (2012) A method for thermal characterization and modeling of large gantry-type machine tools. Int J Adv Manuf Technol 62:875-886. doi:10.1007/s00170-011-3879-0

2. Kennedy B (2008) Larger machine tool issues. Cutting Tool Eng 59:41-48

3. Dhupia J, Powalka B, Katz R, Ulsoy AG (2006) Dynamics of the arch-type reconfigurable machine tool. Int J Mach Tools Manuf 47:326-334
4. Huo D, Cheng K, Wardle F (2010) Design of a 5-axis ultraprecision micro-milling machine-UltraMill. Part 2: integrated dynamic modeling, design optimization and analysis. Int $\mathrm{J}$ Adv Manuf Technol 47:879-890. doi:10.1007/s00170-009-2929-1

5. Ravve I, Gottlieb O, Yarnitzky Y (1997) Nonlinear dynamics and stability of a machine tool traveling joint. Nonlinear Dyn 13:373-394

6. Mhala VP, Grad IE (2008) Contact deformation of machine tool joints using UHMWPE under varying process parameters and environmental conditions. IE(I)J-PR 89:19-24

7. Kolar P, Sulitka M, Janota M (2011) Simulation of dynamic properties of a spindle and tool system coupled with a machine tool frame. Int J Adv Manuf Technol 54:11-20. doi:10.1007/s00170-010-2917-7

8. Duncan GS, Tummond MF, Schmitz TL (2005) An investigation of the dynamic absorber effect in high-speed machining. Int $\mathrm{J}$ Mach Tools Manuf 45:497-507

9. Carrella A, Ewins DJ (2011) Identifying and quantifying structural nonlinearities in engineering applications from measured frequency response functions. Mech Syst Signal process 25:1011-1027. doi:10.1016/j.ymssp.2010.09.011

10. Stry GI, Mook DJ (1992) An experimental study of nonlinear dynamic system identification. Nonlinear Dyn 3:1-11

11. Andersson PBU, Kropp W (2008) Time domain contact model for tyre/road interaction including nonlinear contact stiffness due to small-scale roughness. J Sound Vib 318:296-312

12. Brutti C, Coglitore G, Valentini PP (2011) Modeling 3D revolute joint with clearance and contact stiffness. Nonlinear Dyn 66:531548. doi:10.1007/s11071-010-9931-z

13. Fawzi MA (2011) Time-varying total stiffness matrix of a rigid machine spindle-angular contact ball bearings assembly: theory and analytical/experimental verifications. Shock Vib 18:641-670. doi:10.3323/SAV-2010-0577

14. Yigit AS, Ulsoy AG (2002) Dynamic stiffness evaluation for reconfigurable machine tools including weakly non-linear joint characteristics. Proc ImechE Part B: J Mech Manuf 216:87101

15. Andrew C, Cockburn JA, Waring AE (1967) Metal surfaces in contact under normal forces: some dynamic stiffness and damping characteristics. Proc Instn Mech Engrs 68:92-100

16. Dekoninck C (1972) Deformation properties of metallic contact surfaces of joints under the influence of dynamic tangential loads. Int J Mach Des Res 12(3):193-199

17. Rogers PF, Boothroyd G (1975) Damping at metallic interfaces subjected to oscillating tangential loads. Trans ASME, J Eng for Industry 97(3):1087-1093

18. Shi X, Polycarpou AA (2008) Investigation of contact stiffness and contact damping for magnetic storage head-disk interfaces. Trans ASME, J Tribol 130:021901-021909

19. Liu W, Ewins DJ (2002) Substructure synthesis via elastic media. J $\backslash$ Sound Vib 257:361-379. doi:10.1006/jsvi.5044

20. Schmitz TL, Duncan GS (2005) Three-component receptance coupling substructure analysis for tool point dynamics prediction. J Manuf Sci Eng 127:781-790

21. Marchelek K, Szwengier G, Bodnar A (1999) Experimental investigation of relative coefficients of vibration energy dissipation in slideway joint contacts of machine tools. Comput Methods Exp Meas IX:77-86

22. Ferreira JV, Ewins DJ (1996) Nonlinear receptance coupling approach based on describing function. Proceeding 14th International Modal Analysis Conference, Hawaii 1:1034-1040.

23. Liu H, Zhao WH (2010) Dynamic characteristic analysis for machine tools based on concept of generalized manufacturing space. $\mathrm{J}$ Mech Eng 46:54-60

24. Wen BC, Li YN, Han QK (2001) Nonlinear vibration theory and its application. Northeast University Press, Shenyang 